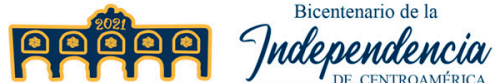

Cleto Ordóñez: Nuestro Héroe Nacional Olvidado por la Historia Convencional, pero sobre todo por la enseñanza.

Mge. Recardo Avilis Salmerion Docente del Departamento de Historia UNAN-Managua.

Master en Estudios Históricos Latinoamericanos y del Caribe.

Orcid: https://orcid.org/0000-0003-2117-0765

Correo: rdaviless@yahoo.com 


\section{Cleto Ordóñez: Nuestro Héroe Nacional Olvidado por la Historia Convencional, pero sobre todo por la enseñanza.}

\section{Cleto Ordóñez: Our Forgotten National Hero by Conventional History, but above all by teaching}

\section{RESUMEN}

Cleto Ordoñez, olvidado por la historiografía nicaragüense, aparece en las páginas de la historia oficial y en los discursos de pocos intelectuales que tímidamente lo mencionan como partícipe en el proceso de Independencia, acá se muestra como este mestizo, debe ser resaltado en la historia nacional como héroe que estuvo al frente de las luchas en pro de la independencia.

\section{ABSTRACT}

Cleto Ordoñez, forgotten by Nicaraguan historiography, appears in the pages of official history and in the speeches of few intellectuals who timidly mention him as participating in the process of Independence, here he shows how this mestizo must be highlighted in national history as a hero who was at the forefront of the struggles for independence.

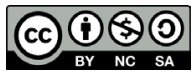

Copyright $\odot 2021$ UNAN-Managu Todos los DerechosReservados.

\section{PALABRAS CLAVE}

Cleto Ordoñez, independencia, héroe, mestizo

\section{KEYWORDS}

Cleto Ordoñez, independence, bero, mestizo

\section{Introducción.}

Los argumentos a continuación presentados, para rescatar la figura y gesta del héroe por la independencia de Nicaragua, Cleto Ordóñez, están basados en distintos autores, que retomaré de manera textual, argumentando o interpretando desde mi punto de vista, porqué este líder mestizo debe tener el reconocimiento de "Héroe de nuestra Independencia", mereciendo un destacado lugar en los murales que todos los años realizan nuestros estudiantes en las efemérides Patrias, pero sobre todo en el corazón de todo nicaragüense amante de la independencia, de la autodeterminación y de la soberanía de Nicaragua, desde el pueblo mismo. La primera vez que tuve referencias de Cleto Ordóñez, fue en la década de la Revolución Popular Sandinista de los años '80 del siglo XX. Siendo profesor de primaria, me interesó saber, quien era el personaje. Luego, insistía en mis clases al indagar, sobre todo con granadinos, sobre la existencia de este mestizo, y nadie me decía nada. Es hasta 2013, siendo parte del colectivo de docentes del departamento de Historia de la UNAN-Managua, siendo rector el maestro Elmer Cisneros Moreira (q.e.p.d.), cuando logramos que la Historia de Nicaragua se volviera a impartir a todas las carreras de esta universidad popular, es que empezamos a visibilizar a Ordóñez. Pero, en los propios murales universitarios conmemorativos a las fiestas Patria, seguía y sigue ausente este autentico héroe popular.

El 8 de agosto de 2019 , se realiza un debate historiográfico sobre la trascendencia de este mestizo, coordinado por Jorge Eduardo Arellano quien lo describe así en http://www.elnuevodiario.com.ni/politica/54235 
Cleto Ordóñez: primer caudillo popular de Nicaragua:

En el Auditorio de la Biblioteca del Banco Central de Nicaragua tuvo lugar el miércoles 22 de julio un panel en que se debatió la actuación histórica de Cleto Ordóñez (Granada, 1778San Salvador, 1839), figura clave de Nicaragua a raiz de la independencia. Coordinador del evento, el suscrito señaló la complejidad de ese proceso formativo del Estado-Nación de Centroamérica, entidad política plasmada en la Constitución de las Provincias Unidas del Centro de América el 22 de noviembre de 1824."

\section{Ordóñez y su personalidad carismática}

En el marco de ese evento, Arellano resalta al doctor Antenor Rosales (en su artículo del NAC, publicado el 28 de marzo de 1998), quien destaca a Ordóñez como hijo de aristócrata y mujer humilde. Se hacía querer de las clases superiores y de las medianas e inferiores.

Alternaba con los miembros del estrato más grande de Granada, en cuyo barrio Santa Lucía había nacido, siendo hijo del capitán español Diego de Irigoyen -quien sería párroco de Managua- y de una negra; por tanto, era mulato e ilegítimo. Así lo puntualizó Eddy Kühl, autor de una reciente semblanza de Ordóñez.

En este sentido, su actuación política significaba el ascenso o movilidad social de ese grupo numeroso que constituía una realidad desde finales del siglo XVIII. La plebe ladina o mulata formaba en 1808 -según los datos de Domingo Juarros-, la mayoría de los habitantes de León y Granada.

En León, sin contar el pueblo indígena de Sutiaba, vivían 5,740 mulatos, mientras los españoles eran 1,061, los mestizos 626 y los indios 144. En Granada se contaban 4,775 mulatos, 1,965 indios (en Jalteva), 960 mestizos y 863 españoles (europeos y criollos). Una mayoría de mulatos o ladinos que en 1820 llegó a sumar el 84 por ciento de la población de la provincia.

Para entonces, Ordóñez -reducido a la servidumbre desde niño- era veterano de la milicia colonial -una de las pocas opciones que ofrecía el sistema a su estrato-llegando a obtener el grado de Sargento y la habilidad de artillero. Pero era rebelde y por ese motivo permaneció preso en un calabozo del puerto de Trujillo, Honduras, de donde se fugó con la ayuda de unos negros, y la salida repentina al aire le produjo estrabismo, por el que le llamarían "el tuerto Ordóñez".

Es importante destacar como en ese debate, los participantes destacan el origen humilde de este personaje, pudiendo explicarse así, porque su ausencia de lo Aldo Díaz Lacayo, señala como Historia Convencional. No es casualidad, que otros grandes personajes de nuestra Historia, hayan sufrido en sus primeros años esa situación de pobreza.

Continua destacando Arellano, que también había sido pequeño comerciante, realizando viajes a Belice e introduciendo de contrabando mercancías inglesas a Matagalpa y las Segovias; ello le facilitó la adquisición de una "pequeña fortuna y roce social que le daba cierta superioridad", según el cronista Francisco Ortega Arancibia, quien destaca además que era "hijo del pueblo y con grandes simpatías en las masas, Cleto Ordóñez gozaba de muchas consideraciones en las casas de las familias ricas, como la del coronel Sacasa y otras...." 
En otras palabras, hacia 1821 Ordóñez no sólo había superado las posibilidades económicas que limitaban a la gente de su extracción social y racial, sino que imponía su personalidad en todos los estratos. Asimismo, era médico herbolario, es decir, curandero; poeta espontáneo --autor de unas décimas a la Libertad-- y orador de barricada.

Tomaba las alturas de las plazas o en las esquinas lo subian sobre sus hombros los soldados para que arengara a las masas, y con su ardiente palabra encendía el fuego del entusiasmo en el pecho de los patriotas granadinos. Además, pulsaba la guitarra, paseaba, jugaba, mas no era aficionado al licor. Sus vicios dominantes eran el fumado y el amor libre".

\section{El Plan de Iguala}

Según Andrés Pérez Baltodano en su obra "Del Estado conquistador al Estado nación... Luis Alberto Cabrales (1901-1974): "se refería al Plan de Iguala, firmado el 24 de febrero de 1821 en México, entre Agustín de Iturbide y Vicente Guerrero. Llamado también de "Las tres garantías" (religión, unión, independencia). Dicho Plan condujo a los criollos guatemaltecos a entenderse con el último representante de la monarquía española, Gabino Gainza, para proclamar la independencia en esos términos. Así lo había realizado el Estado de Chiapas, perteneciente a dicho Reino."

Pues bien, basados en la obra señalada, el 15 de septiembre asistieron en la capital de Guatemala dos bandos: unos pocos que se oponían a la independencia (altos funcionarios y eclesiásticos obstinados, más algunos comerciantes españoles monopolistas) y la mayoría que la consideraba impostergable y habían llegado a proclamarla siguiendo la orientación monárquica del Plan de Iguala.

A este segundo bando pertenecía el propio Gainza, quien encabezaba la línea criolla, concepción independentista oficial: planeada previamente por peninsulares y españoles americanos, predominaba entre todas las autoridades coloniales.

\section{La presión del tercer bando no invitado}

Baltodano destaca la presencia de un tercer bando, no presente aquel 15 de septiembre, cosa que nunca hemos enseñado en las aulas. Lo destacan como un tercer bando -que no estaba invitado- presionó a la última hora para que se variase de criterio y las mismas autoridades tuvieron que proclamar la independencia tal como la concebían los liberales: sin anexión, o sea: en forma absoluta.

Ante la exigencia de la plebe, acaudillada por elementos de la capa media alta urbana -como el doctor Pedro Molina (1777-1854) y su esposa Dolores -la actitud de los criollos tuvo que ceder. De manera que en esta ocasión triunfó la línea independentista liberal. Pero el 5 de enero de 1822 se impuso el plan anexionista. En esa fecha, los criollos guatemaltecos se adhieren al Plan de Iguala, que proponía como Emperador al propio Fernando VII o a otro miembro de la familia reinante.

En León, desde octubre de 1821, la Diputación Provincial, el clero y el claustro de la Universidad habían jurado, "la absoluta independencia del gobierno español bajo los auspicios del imperio mexicano". Optaron por la anexión. Dos de sus principales representantes eran el obispo Nicolás García Jerez (1757-1825) y el Intendente Miguel González Saravia (ambos españoles y acérrimos defensores del abolido antiguo régimen). Según Aldo Díaz Lacayo, en su obra "Las tres Revoluciones Independentistas de América", libro de 


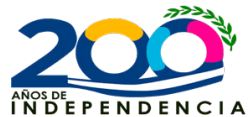

obligatoria lectura para los docentes que queremos superar la visión limitada de la Historia Convencional, el proceso de Independencia es el inicio de la contradicción entre Liberales (mestizos granadinos) y Conservadores (oligarcas leoneses), pero como una paradoja, ya que nos han enseñado siempre que Granada es conservadora y León liberal. Díaz destaca:

Granada se pronunció a favor de la Independencia y posteriormente a la anexión a México, una decisión esta última rechazada militarmente por el pueblo granadino dirigido por los mestizos."

La Anexión a México fue una clara muestra de que la oligarquía nunca ha compartido ni practicado el principio de autodeterminación y soberanía, el derrumbe del imperio mexicano, según Pérez Baltodano, dejó a las élites pro-imperialistas de Granada desprotegidas y expuestas frente al poder militar y al arrastre del movimiento popular anti-imperialista liderado por Cleto Ordóñez, quien el 16 de enero de 1823, dos meses antes de la caída de Iturbide, se había apoderado del cuartel de la ciudad para luego establecer un gobierno republicano. $Y$ es que ya en ese marco de la nueva pugna entre anexionistas y republicanos, es que surgió, con fuerza, Cleto Ordóñez como líder de los barrios granadinos y aliado con algunos criollos liberales, entre ellos Juan Argüello y Manuel Antonio de la Cerda (protagonistas del movimiento insurgente de 1811 y 1812).

Frances Kinloch explica esta situación:

Respaldado por una Junta Patriótica integrada por elementos progresistas de las clases medias y algunos criollos liberales, [Ordónez] profundizó las reformas emprendidas al orden colonial: abolió el derecho estamentario, así como los títulos, tratamientos y privilegios de la aristocracia criolla. El pueblo se encargó de hacer cumplir los decretos revolucionarios: Al grito de 'iSe acabaron los dones!', recorría las calles de Granada, arrancando de las fachadas de las casonas señoriales los escudos nobiliarios que simbolizaban el viejo orden". (Kinloch, 1990, 71)

Es importante destacar que, como todo movimiento de dicha naturaleza, clasista sobre todo, desata acciones incontrolables, que para nada deben deslegitimar el fondo de las gestas. Kinloch describe que, encabezando el bando republicano, Ordóñez rechazó militarmente en Granada a las fuerzas de González Saravia el 13 de febrero de 1823. Pero este triunfo desató el saqueo y la expropiación como botín político. Sus partidarios allanaron 39 casas adineradas. Concretamente, mujeres del pueblo se apropiaron de alhajas, telas, vestidos, muebles, enseres de cocina y alimentos; con ellos, en suntuosos banquetes improvisados, se obsequiaban a la muchedumbre manjares y licores de la mejor calidad En este sentido, para la visión conservadora y oligárquica de la Historia, un "ladrón y saqueador" no merece ser héroe. Emilio Álvarez Montalván en su libro "Cultura Política Nicaragüense" es un fiel representante de esa corriente anteriormente destacada. Afirma, hasta creo yo, en un tono despectivo que:

El escenario controversial descrito estaba limitado al litoral del Pacifico y a la zona central, pues como ya dijimos la costa oriental fue ajena a esos conflictos. Fue una lucha insensata, pues ninguna de aquellas ciudades capitanas tenía en ese momento capacidad, ni de someter totalmente a la otra ni de asumir sola las responsabilidades de mantener el orden, costear un ejército y financiar una burocracia en toda la República. Eran como dice BURNS, "Estados-ciudades agrarias, empobrecidas, pretenciosas y desvinculadas, incapaces de estructurar una identidad nacional». Por supuesto que esa confrontación de tipo localista estaba asociada y estimulada por personalismos y luchas de clanes entre sí, que encontraban en ella el ambiente propicio para expresarse, como la rivalidad entre Cleto Ordóñez y Crisanto Sacasa. Sin embargo, las causas eran mucho más profundas, pues no eran otra que 
la dificultad de desarrollar un minimo de solidaridad en una sociedad dispareja, en educación, ingreso económico y posición social, lo que ha convertido a Nicaragua en una sociedad dual.

Resulta, entonces, que nuestros partidos políticos surgieron a la vida pública con defectos congénitos, llenos de distorsiones y limitaciones en cuanto a representatividad del universo nacional, cargados de rencor y revancha, guiados por dirigentes de gran imaginación, que halagaban a su clientela con proyectos fantásticos. Al final cuando no lograban realizar sus promesas al llegar al poder, surgía una doble frustración, tanto del gobernante que se veía impedido de realizar sus promesas como del que no lograba ver satisfechas sus necesidades básicas. En esos años en que se formaban los partidos políticos, (década de 1820) el espíritu festivo nicaragüense, que no asignaba al pleito mayor importancia, les asignó nombres burlescos a aquellos sectores políticos, algunos por cierto peyorativos."

Como asegura, sigue diciendo Álvarez Montalván, GÁMEZ: “Los Liberales con la camándula en una mano y con la bandera roja en la otra y comandados por Cleto Ordóñez se mancharon con robos y saqueos en Granadaj". (Álvarez, 2006: 142-143) Por su parte, como parte de esa visión oligárquica, Enrique Bolaños Geyer en "Trozos de Historia: La Independencia”, resalta a Ordóñez de la siguiente manera:

Anacleto (Cleto) Ordóñez (granadino, soldado, comerciante, curandero, poeta popular, agudo de ingenio), descontento por la anexión de Nicaragua al Imperio mexicano, ofrece el derecho al saqueo a los que le apoyaran, y el 16 de enero de 1823 tomó sin derramamiento de sangre el Cuartel militar de Granada, pero en su lucha por la causa contra la anexión a México, desató una ola de terror revestida de saqueos, despojos y atracos, no sólo en Granada, sino también en Masaya, Jinotepe, Juigalpa y otros lugares."

Por eso, hay que destacar que todo este asunto es más de fondo. Según el prócer liberal centroamericano, Pedro Molina, Ordóñez se había tomado el Cuartel de Granada el 23 de enero de 1823 proclamando la república. En sus memorias, Pedro Molina lo consignaría:

Desmoronábase ya el Imperio mexicano, cuando el caballero de Granada (Crisanto Sacasa) imaginó evadirse del pago de una gruesa suma, suscitando una conmoción popular a efecto de que se persiguiese a su acreedor. Por ello se confabuló con un hombre atrevido y de talento que deseaba, por motivos más nobles, arrebatar su patria al yugo imperial, para que se echase sobre el Cuartel de la Guarnición. Sucedió así y los cabecillas de la conspiración lograron sus fines, escondiéndose el primero y poniéndose al frente el segundo. Este fue Cleto Ordóñez, que de cabo primero de artillería pasó a comandante de las armas granadinas."

Con la consolidación del poder del caudillo, el conflicto político nicaragüense iba a adquirir un perfil más claramente clasista. Según Pérez Baltodano, las autoridades de León reaccionaron ante la caída de Iturbide abandonando sus inclinaciones pro-imperialistas y firmando la llamada Acta de la Orfandad el 17 de abril de 1823 (Esgueva, 1993, 18-19). De acuerdo a Chester Zelaya, los principales responsables de este documento fueron los representantes de los sectores sociales de orientación liberal, dentro de los que se destacaban los estudiantes.

Recordemos, es importante creo yo, contextualizar el asunto, para que los jóvenes de hoy no trasladen mecánicamente las situaciones y a su vez destaquen lecciones de la historia con la vigencia de algunos hechos. En el acta se señalaba: "Que considerándose las Provincias en estado de horfandad por las ocurrencias del Imperio, están en estado de libertad para poder constituir su Gobierno". Además, establecía 


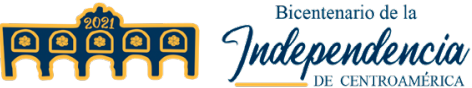

la formación de una Junta de Gobierno Republicana de orientación popular, que ejercería "las facultades del Gobierno Soberano".

Ante la consolidación del poder de los sectores progresistas liberales, los líderes del movimiento proimperialista de León, incluyendo al obispo Nicolás García Jerez, abandonaron la ciudad. Muchas de las familias "propietarias" de la ciudad escaparon hacia Managua, imitando de esta manera, la conducta de las familias ricas de Granada. (Zelaya, 1971, 169-173) En Managua, formaron un gobierno paralelo al que controlaba Ordóñez en Granada y otras familias pertenecientes a las clases propietarias que aún permanecían en León, escaparon hacia El Viejo en donde establecieron otro gobierno paralelo a la Junta Militar de León controlada por Ordóñez. Según Luis Cabrales en el evento del Banco Central ya referido, “Cleto Ordóñez es el primer caudillo popular de Nicaragua, y el heroico defensor del régimen republicano de la lucha contra los imperialistas, partidarios de Iturbide". Esta premisa fue compartida por todos los expositores de dicho debete (2009).

Otro elemento del ordoñismo fue el resentimiento social antinobiliario. Pero no se manifestó sino después que -más adelante se abordará este aspecto- la Asamblea Nacional Constituyente de la Federación Centroamericana decretase la abolición de todos los tratamientos de Majestad, Excelencia, Señoría, etc. Quedó abolida, asimismo, la distinción de Don, no debiendo tener todos los individuos de la república otro título que el de Ciudadano. La consigna era “iAbajo los dones!”.

En referencia a Pedro Chamorro, del 23 de noviembre de 1823, en una comunicación dirigida al presbítero Ignacio Solórzano, decía:

Siendo las insignias de condecoración y en ese contexto, Ordóñez decidió destruir los escudos y otros distintivos nobiliarios de algunas familias granadinas de origen español (exceptuando las de sus aliados). La orden correspondiente además de distinción, e igualmente las armas Imperiales y del antiguo Gobierno Hispánico, monumentos tristes de la opresión y degradación, muy contrarias al liberalismo actual del sistema: debiéndose dar puntual cumplimiento al decreto de la A. N. C. del 4 del corriente; espero que usted como encargado de la casa e intereses del señor Pedro Chamorro, se servirá disponer que dentro de tres dias haga desaparecer de la portada de dicha casa las armas que esculpidas en piedra, y aún en lo interior de aquellas pintadas en lienzo [pared], hacen la significación más vilipendiosa en el siglo de las luces y de la despreocupación, que se resiente aún en el recuerdo de injustas distinciones".

Según Jerónimo Pérez, "he ahí el retrato de esta figura carismática y popular que "encarnó la revolución de la Independencia" y representó "realmente al pueblo de los barrios granadinos y al de Nicaragua en general, anarquizados por la división de los señores principales". O sea que, optando por la tendencia afín de su interés de clase, tomó la decisión de enfrentarse a los "serviles aristócratas"; así denominaba al bando de cohesionado por Crisanto Sacasa. Porque él se consideraba libre y creía en los principios liberales, como la igualdad ciudadana, aunque careciese de formación intelectual.

En el fondo, su liberalismo era de carácter instintivo e intuitivo, sustentado en su inteligencia natural y en su capacidad de convocatoria entre la mayoría ladina y otros militares, como él. Y así llegó a ser el caudillo de los liberales rojos y árbitro de los destinos del país y a tener el reconocimiento el prócer independentista Pedro Molina, quien en una carta que le dirigió desde Guatemala el 22 de julio de 1823, le decía: “Ambos 
somos liberales: ruego a Dios guarde su vida muchos en defensa de la patria". En otro reportaje se ampliará sus acciones históricas. Aldo Díaz destaca:

Fue el primer deslumbramiento mestizo en Centroamérica y el primer intento de revolución liberal en Nicaragua con la demanda explícita del republicanismo, dirigida por Cleto Ordóñez (1823). Coincidencia mestizo-revolución que se mantendrá en el tiempo, siempre marcada por las contradicciones sociales y la agresión externa. Fue una revolución fugaz, es cierto, porque inmediatamente se derrumbó el imperio de Iturbide, obligando, como ya se dijo, el replanteamiento de la Independencia a nivel ístmico. Pero dejó huella. Primero porque logró enfrentar exitosamente a las fuerzas provinciales enviadas por León para sofocarla, y porque su principal decreto contra peninsulares y criollos promonárquicos, aboliendo el tratamiento social diferenciado, fue recogido integramente por la Asamblea Constituyente de la República Federal."

Ahora bien, siguiendo con el análisis del contexto histórico de las obras citadas, para aclarar la confusa situación política de Nicaragua, las autoridades de León y Granada se reunieron en Masaya el día 26 de abril de 1823. Este encuentro produjo como resultado el tratado de paz de Masaya, que estableció que eran "libres los pueblos de ambos Gobiernos [León y Granada] en la comunicación recíproca, y relaciones de amistad y comercio, guardándose la más estrecha armonía". También estableció que "los pueblos" eran "libres a adherirse a uno, u otro Gobierno..." (Tratado de Masaya, 1823, en Esgueva, 1993, 120) Así pues, el tratado de Masaya creó un marco de relaciones entre dos "ciudades-estados" (Arellano, 1997a, 22).

Este acuerdo formalizó el localismo y expresó la incapacidad del movimiento popular nicaragüense para articular una visión y un consenso de intereses y aspiraciones de alcance nacional. Lección que siempre es vigente en las luchas populares: ¡Mantener la Unidad!

Según Arellano, ya a partir del $1^{\circ}$ de julio de 1823 , tales provincias se habían independizado en forma absoluta tanto de España como del Imperio de Agustín de Iturbide, al que estuvieron adscritas desde el 5 de enero de 1822, cinco meses después de la proclamación en Guatemala de la independencia de la monarquía española el 15 de septiembre de 1821.

Por tanto, en menos de cuatro años quienes habitaban el territorio del istmo centroamericano fueron vasallos del rey de España, ciudadanos independientes de esa potencia europea en crisis, súbditos del Imperio Mexicano y ciudadanos de la Federación, es decir, cuatro identidades políticas distintas.

Mientras Nicaragua vivía esta caótica situación, se creó la República Federal, el 1 de julio de 1823. Sus autoridades encomendaron a José Justo Milla la misión de poner fin al conflicto nicaragüense. La misión de Milla fracasó en mayo de 1824, cuando un grupo de militares leoneses se levantó en armas para oponerse a la intermediación de Guatemala. Los rebeldes fueron depuestos pocos días después por militares que simpatizaban con Ordóñez. De esta forma, el caudillo logró unificar bajo su mando "las voluntades" de los gobiernos de León y Granada. (Zelaya, 1971, 211)

Por otro lado, en 1824, cuatro diferentes gobiernos se disputaban el control del naciente Estado nicaragüense (Burns, 1991, 41): Un gobierno leonés ubicado en El Viejo y otro granadino con sede en Managua representaban los intereses de las clases propietarias de las dos ciudades; y los gobiernos de León y Granada, liderados por Ordóñez, que representaban los intereses de las clases populares.

El trasfondo clasista de la guerra que se desató, a partir de esta confusa situación, la confirma Ayón al señalar que en esta contienda "se vieron unidos los antiguos realistas e imperialistas con los republicanos moderados, para defenderse de lo que hoy llamarían la "Commune". En la guerra de 1824, señala Gámez, 


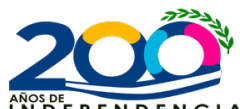

ANNOSDE PEN DENCIA

combatieron "pueblos contra pueblos, familias contra familias, parientes y vecinos, unos contra otros, sin otro móvil que el insensato deseo de destruirse".

Y agrega:

El país quedó devastado, las haciendas abandonadas y muchas personas ricas se encontraron sin abrigo solicitando la caridad en los caminos. Los crimenes, que no podian castigarse durante la contienda se multiplicaron asombrosamente con la impunidad, y los asesinatos, robos y violaciones con el sexo débil, se cometieron sin restricción alguna. Guerra semejante tuvo que ser el desahogo de innobles pasiones, nunca jamás la expresión de partidos políticos y mucho menos el desborde de un patriotismo exagerado". (Gámez, 1889/1975, 369)

El conflicto entre las clases populares y las clases propietarias nicaragüenses terminó siendo aplacado en enero de 1825 por la intervención de tropas federales centroamericanas comandadas por el general Manuel José Arce. Estas intervenciones representan el inicio de una constante histórica que se mantendrá a través del proceso de formación del Estado nicaragüense: la participación de fuerzas externas en la solución de los conflictos domésticos del país, destaca Pérez Baltodano, sobre todo, agregaría yo, la oligarquía no solo acepta dicha solución, sino que la pide a gritos cuando las fuerzas populares afectan sus intereses y los de sus amos imperiales. Arce descabezó el movimiento popular nicaragüense al nombrar a Ordóñez como inspector general de armas de la República Federal. Este nombramiento obligó a Ordóñez a trasladarse a Guatemala y a retirarse del escenario político nicaragüense. Arce, además, organizó elecciones para escoger a los miembros de una Asamblea Constituyente y al jefe y vice jefe de Estado. Una clara maniobra política, si no te destruyen o te derrotan, te neutralizan.

La guerra, además del costo humano y material, "que representó para Nicaragua, empujó a los habitantes del distrito de Nicoya o Guanacaste a anexar esta porción de territorio nicaragüense a Costa Rica en julio de 1824." (Gámez, 1975, 370). (Pérez, 2003: 137-139) Y también lo empujó las maniobras de la oligarquía de nuestro vecino país al repetir el referéndum, que inicialmente sus resultados con todo y todo, les fue adverso.

\section{La trascendencia de la gesta de Ordóñez}

Mientras el Congreso Centroamericano preparaba la Constitución Federal, las antiguas provincias de la región redactaban sus propias Cartas Constitucionales para legalizar su condición como Estados Federados. La Constitución centroamericana se proclamó en noviembre de 1824. El Salvador también la proclamó ese mismo año. Costa Rica, Guatemala y Honduras lo harían en 1825. Nicaragua, consumida por la guerra, en 1826. (Karnes, 1982, 58-59)

Esta Asamblea Constituyente de lo que sería la República Federal, en efecto, decidió la abolición de los tratamientos de Majestad, Alteza, Excelencia, Señoría, Don (José Dolores Gámez), tal como lo había hecho Cleto Ordóñez, quien también abolió los blasones. La historia convencional obviamente no reconoce esta decisión revolucionaria, en el mejor de los casos la califica de resentimiento social. Incluso la oculta para negarle capacidad intelectual a Cleto Ordóñez. Para ocultar la evidente naturaleza ideológica de sus demandas políticas. (Díaz, 2013:185-186) Un último episodio del cual tengo referencia en este apretado resumen, es que el 14 de septiembre de 1827 Cleto Ordóñez, Comandante General de las armas, derroca al Jefe Supremo del Estado Juan Argüello, aspirando a salvar el sistema político del país, que se había sumido en la anarquía. 


\section{Conclusiones}

El hecho de rescatar la figura de un personaje histórico que desafío a la aristocracia criolla y su protagonismo en la lucha independentista desde los años 1811-1812, de ser un promotor de la independencia total frente al imperio español, de ser caudillo muy unido a las aspiraciones populares frente al monarquismo impuesto por el imperio mexicano, de ser un convencido de las bondades del sistema republicano, de ser un defensor del proyecto federal y del centroamericanismo, pero sobre todo de ser y provenir de las clases populares y luchar por su reivindicación frente a la oligarquía, igual que lo hizo hasta su muerte el presbítero indígena Tomás Ruíz.

Por eso, el propio presidente Daniel Ortega lo resaltó en su discurso del 15 de septiembre de 2020, iniciando la jornada del Bicentenario de nuestra Independencia. Pero el comandante Ortega lo viene reivindicando como héroe popular desde la lucha antisomocista, cuando en la jornada Octubre Victorioso, el cual se considera el nacimiento del Frente Norte "Carlos Fonseca" en 1977, usaba como seudónimo el nombre del mestizo heroico "Cleto".

Por todo lo anterior y muchas cosas más, el sistema educativo nacional debe rescatar del anonimato y del olvido del pueblo, pero sobre todo de las futuras generaciones a nuestro héroe por la Independencia Cleto Ordóñez, quien hoy como ayer, levanta con insistente vigencia su consigna ¡Abajo los dones!

\section{Referencias bibliográficas.}

- Urtecho J.C (1962) “Reflexiones sobre la historia de Nicaragua”. (De Gainza a Somoza). Editorial Hospicio. León. Nic.

- Pérez-Baltodano, Andrés (2003) Entre el Estado Conquistador y el Estado Nación: Providencialismo, pensamiento político y estructuras de poder en el desarrollo histórico de Nicaragua. Instituto de Historia de Nicaragua y Centroamérica Universidad Centroamericana, Fundación Friedrich Ebert, Managua.

- Kinloch Tijerino, Frances (2012) Historia de Nicaragua. Managua, IHNCA, 4ta. Ed.

- $\quad$ Esgueva, Antonio (1999) Conflictos y Paz en la Historia de Nicaragua. Taller de Historia No. 7. Managua. IHNCA-UCA.

- Dïaz Lacayo, Aldo (2013) Las Tres Revoluciones independentistas de América desde la Historia de Nicaragua. Aldilá Editor.

- Cleto Ordóñez: primer caudillo popular de Nicaragua. Por: Jorge Eduardo Arellano Debate historiográfico. 8 de agosto de 2009 http://www.elnuevodiario.com.ni/politica/54235 